\title{
Renewable based Multicarrier PWM Topology for Symmetric MLI
}

\author{
J. Gayathri Monicka ${ }^{\# 1}$, K. Dwarakesh ${ }^{\# 2}$, C.Amutha Devi ${ }^{* 3}$ \\ "Department of Electrical and Electronics Engineering, \\ Adhi College of Engineering and Technology,Kanchipuram, India. \\ ${ }^{1}$ gayathri.eee@adhi.edu.in \\ 2dwarakesh7281@gmail.com \\ *Department of Computer Science and Engineering, \\ Misrimal Navajee Munoth Jain Engineering College, Chennai \\ camuthadevi@gmail.com
}

\begin{abstract}
In this work, the operation and performance of photovoltaic fed Symmetric Cascaded Multilevel inverter (CMLI) is investigated and presented. CMLI is one of the widely used types of converter. Source for Multi-level inverters (MLI) is fed using a renewable energy system. A PV array has been designed using mathematical models. With increased number of levels at the output, harmonics content has been reduced and finds application at high power sectors. This work proposes CMLI with equal DC Sources, using various type of level shifting Multicarrier PWM technique. Owing to their ease, flexibility and less computational requirements, carrier based approaches have been widely used for switching the power semiconductor devices of MLI's. Harmonic performances have been improved by using PWM strategy for the modulated cascaded inverters. The design Performance of CMLI is evaluated by MATLAB/SIMULINK simulation. Harmonic spectrum of the system is improved by appropriate modulation technique.
\end{abstract}

Keyword-Cascaded Multi-Level Inverter, PV cell, Pulse Width Modulation, Phase disposition,THD

\section{INTRODUCTION}

From last three decades, the area of high-power drives has become the most active research field, The Multilevel Inverter (MLI)approach allows using the high-power and high-voltage electric motor drive systems, which can be implemented using energy resources using equal distribution such as photovoltaics and fuel cells[1]. Few devices like ultracapacitors and batteries which store energyhave been used with MLI's. The required voltage have been obtained from different DC sources like battery and renewable energy system, this are blended through SDCSs with CMLI [2]. In recent times MLI has gained wide popularity in various grid and variable speed drive applications, coming to their advantages, MLI reduces the harmonics in the output waveform with no change in the switching frequency or reducing the output produced from inverter [3].CMLI is the most popular technique among diode clamped and flying capacitor as it has more advantages in harmonic reduction, low switching stress and high voltage gain[4- 6]. The CMLI has the drawback as it needs separate dc sources, butmodularised circuit design is compact and it has no problem of voltage sharing. Hence it is easy to expand, it is applicable in high power motor drives. This paper reports the progress of control methods for cascaded multilevel inverters. Emerging Level shifting modulation control technique has been designed and discussed. Results are presented which reveal the efficiency for the proposed control.

\section{CASCADED MULTILEVEL INVERTER}

CMLI has a distinctive and attractive topology such as simplicity in structure, usage of lesser number of components. Required voltage for the CMLI is obtained from different sources of DC voltages obtained from battery or renewable energy system. The structure of single phase CMLI is depicted in Fig.1. Each separate DC source is associated with a single H-bridge. Five H- Bridges are present for eleven level symmetric CMLI. Source fed for the H-bridges H1, H2, H3, H4, H5 is DC source, $\mathrm{V}_{\mathrm{dc}}$. The AC terminal voltages of diverse levels are connected in series [7]. Through different combinations of the four switches (S1-S4), each inverter level can generate three different voltage outputs, $+V_{\mathrm{dc}},-\mathrm{V}_{\mathrm{dc}}$ and zero. In this topology, the count for output levels of the phase voltage is given by,

$$
p=2 q+1
$$

where, $\mathrm{q}$ is the number of DC sources, $\mathrm{p}$ is the number of levels. The maximum output phase voltage of these $q$ CMLI is

$$
\mathrm{V}_{0}, \mathrm{MAX}=\mathrm{q} \mathrm{V}_{\mathrm{dc}}
$$

The eleven level MLI output will be obtained as depicted in Fig. 2. Number of voltage sources used is five cells, i.e., referred from equation 1.Each cell consisting of a half bridge or full bridge combination of IGBT switches. The switching state for the 11 level inverter is given in Table 1.The switching patterns for the switches 
in the upper leg are mentioned, and that for the lower switches would be the complement of the upper switches [8].
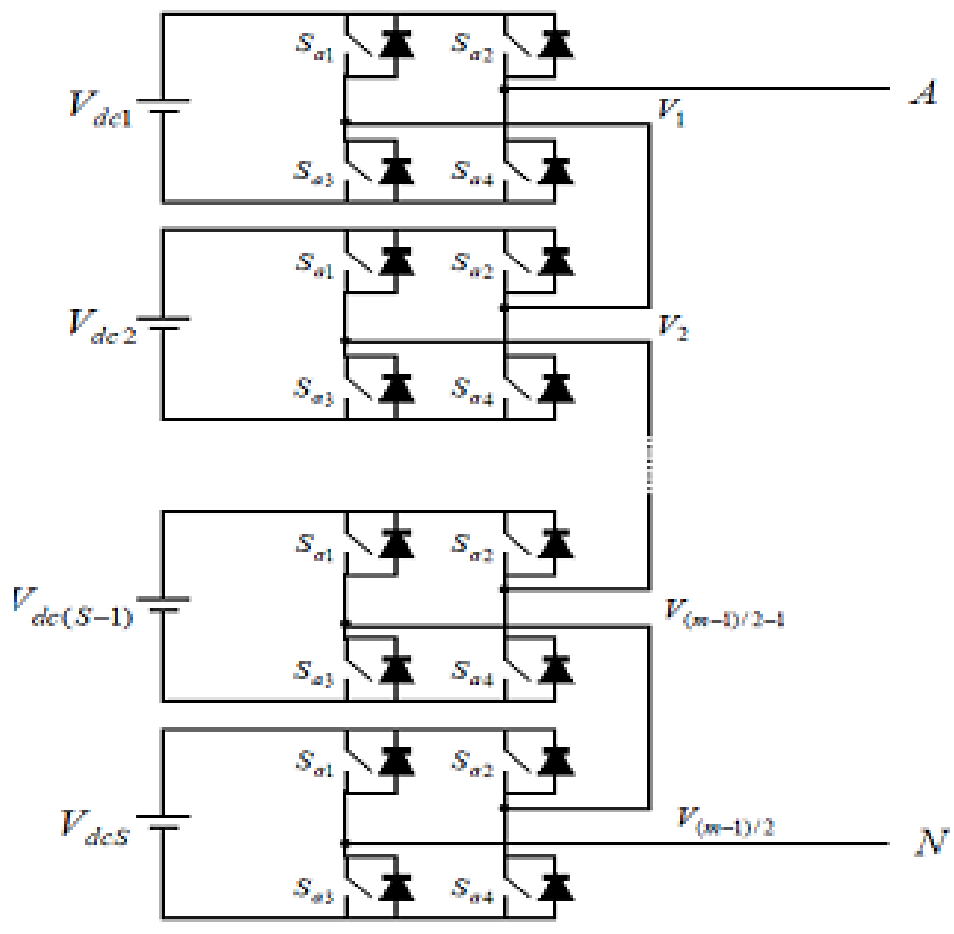

Fig. 1.Structure of a cascaded multilevel inverter.

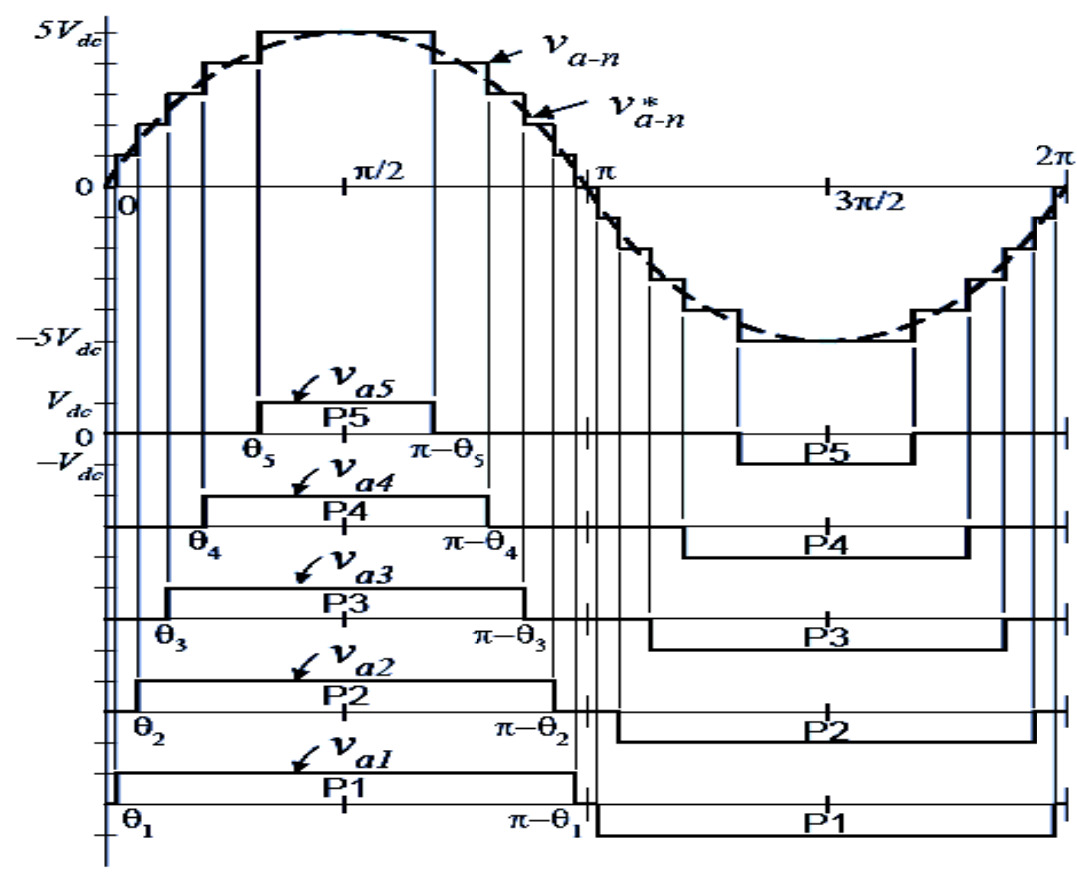

Fig. 2. An eleven level multilevel inverter output.

The number of voltage levels $(\mathrm{m})$ in the phase voltage of symmetrical CMLI inverter is $\mathrm{P}=2 \mathrm{Q}+1-1$, if $\mathrm{V}_{\mathrm{dc}}=2 \mathrm{k}-1 \mathrm{~V}_{\mathrm{dc}}, \mathrm{k}=1,2,3, \ldots \mathrm{Q}$

Where $\mathrm{Q}$ is the number of $\mathrm{H}$-bridge cells per phase Leg. The maximum output phase voltage of these $Q$ cascaded multilevel inverters is

$$
\mathrm{V}_{0}, \mathrm{MAX}=(2 \mathrm{~N}+1-1) \mathrm{V}_{\mathrm{dc}}
$$

The total number of active switches in the CML inverters is calculated by

$$
\mathrm{Q}_{\mathrm{sw}}=4 \mathrm{Q}
$$


TABLE I. Switching state of 11 level Multicarrier PWM

\begin{tabular}{|c|c|c|c|c|c|c|c|c|c|c|}
\hline $\begin{array}{l}\text { Output } \\
\text { voltage }\end{array}$ & S1 & S2 & S3 & S4 & S5 & S6 & S7 & S8 & S9 & $\mathrm{S} 10$ \\
\hline $5 \mathrm{Vdc}$ & 1 & 0 & 1 & 0 & 1 & 0 & 1 & 0 & 1 & 0 \\
\hline \multirow{2}{*}{$4 \mathrm{Vdc}$} & 1 & 0 & 1 & 0 & 1 & 0 & 1 & 0 & 0 & 0 \\
\hline & 1 & 0 & 0 & 0 & 1 & 0 & 1 & 0 & 1 & 0 \\
\hline \multirow{2}{*}{ 3Vdc } & 1 & 0 & 1 & 0 & 1 & 0 & 0 & 0 & 0 & 0 \\
\hline & 1 & 0 & 0 & 0 & 1 & 0 & 1 & 0 & 0 & 0 \\
\hline \multirow{2}{*}{ 2Vdc } & 1 & 0 & 1 & 0 & 0 & 0 & 0 & 0 & 0 & 0 \\
\hline & 1 & 0 & 0 & 0 & 1 & 0 & 0 & 0 & 0 & 0 \\
\hline Vdc & 1 & 0 & 0 & 0 & 0 & 0 & 0 & 0 & 0 & 0 \\
\hline \multirow{3}{*}{ 0 } & 1 & 0 & 1 & 0 & 0 & 1 & 0 & 1 & 1 & 0 \\
\hline & 0 & 0 & 0 & 0 & 0 & 0 & 0 & 0 & 0 & 0 \\
\hline & 1 & 0 & 0 & 1 & 1 & 0 & 0 & 1 & 0 & 0 \\
\hline -Vdc & 0 & 1 & 0 & 0 & 0 & 0 & 0 & 0 & 0 & 0 \\
\hline \multirow{3}{*}{$-2 V d c$} & 1 & 0 & 0 & 1 & 1 & 0 & 0 & 1 & 0 & 1 \\
\hline & 0 & 1 & 0 & 1 & 1 & 0 & 0 & 1 & 0 & 0 \\
\hline & 0 & 1 & 0 & 0 & 0 & 1 & 1 & 0 & 0 & 1 \\
\hline \multirow{2}{*}{$-3 V d c$} & 0 & 1 & 0 & 1 & 0 & 1 & 1 & 0 & 0 & 1 \\
\hline & 0 & 1 & 0 & 1 & 0 & 1 & 0 & 0 & 0 & 0 \\
\hline \multirow{2}{*}{$-4 \mathrm{Vdc}$} & 0 & 1 & 0 & 1 & 0 & 1 & 0 & 1 & 0 & 0 \\
\hline & 0 & 1 & 0 & 1 & 0 & 0 & 0 & 1 & 0 & 1 \\
\hline$-5 V d c$ & 0 & 1 & 0 & 1 & 0 & 1 & 0 & 1 & 0 & 1 \\
\hline
\end{tabular}

Another aspect of the CMLI proposed herein is that dc sources with PV cell must be provided [9-11]. It is preferred to have dc sources of the same value for voltage. Photovoltaic system directly change slight emitted from the sun into electricity. The elementary device of a Photo Voltaic system is the Photo Voltaic cell. Cells are combined to form a structure which is called Solar panels or PV arrays. The output obtained at the ends of a PV device may unswervingly feed minor loads like lighting systems and direct current motors. Solar panel is fundamentally made from semiconductor diodes, PN junction of the diode is exposed to sun. Photovoltaic cells are prepared by using quite a few types of semiconductors by diverse engineering processes [12]. The occurrence of sunrays on the panel which consists of cells produces charges that initiate an electric current when cell is short-circuited. The output of solar panel is dissimilar all over the day; it differs with altering temperature and insulation. Hence with fluctuating temperature and insulation maximum power must be followed to accomplish the effective performance operation of solar panel.

For Q level inverter, the number of DC source $(\mathrm{P})$ required is $(\mathrm{Q}-1) / 2$. For 11 level inverter, 5 DC sources are used, each source is connected to H-bridge cell and each bridge consists of 4 switches, therefore the total count of switches used is 20. By using equal DC source, each DC source is given with 65 Volts, and therefore the total supply voltage equals 325 Volts.

The pulses are generated as given in Table I. Switching positions are established for positive, negative and zero voltages as each of the patterns given in the switching Table I. The produced gate pulses are set to each switch in agreement with the established pattern and thus the output is obtained. The system is connected for a load. The waveform obtained for the MLI is depicted in Fig. 8.TheFast Fourier Transforms analysis is done for the 11 level MLI, it is depicted Fig. 9. 


\section{MULTI-CARRIER PWM}

To generate the desired inverter voltage, diverse modulation schemes where introduced. In industry, commonly applied modulation methods are the carrier-based sine-triangle modulation method [13]. The multicarrier PWM technique uses numerous triangular carrier signals, keeping only one modulating sinusoidal signal .If a ' $\mathrm{q}$ ' level inverter is active , ' $\mathrm{q}-1$ ' carriers are needed. The carriers will have the similar frequency and peak to peak amplitude and are disposed. The zero orientation is located in amidst of the carrier set [14-16]. The modulating signal is a sinusoidal of frequency $50 \mathrm{~Hz}$. At each instant, collectively each carrier is compared with the modulating signal. Each evaluation gives a modulating signal which is larger than the triangular carrier, zero otherwise. In the carrier-based multilevel modulation, every level in a phase needs own carrier. In all levelshifted PWM methods, the carriers of the modules have a frequency of $f$ car $=1 / T \mathrm{sw}$ and an amplitude of the module DC link voltage $V_{d c}$. The reference voltage on the other hand can have values between $-\mathrm{PV}_{\mathrm{dc}}$ and $P \mathrm{~V}_{\mathrm{dc}}$. There are three different types of level shifted modulation techniques, namely

- Phase Opposition Disposition

- Alternative Phase Opposition Disposition

- Phase Disposition

The modulation policy engaged in the circuit is Phase Disposition (PD), all the carriers are in phase across all the bands. This gives growth to the least harmonic in the higher modulation indices, when compared to the other disposition methods. The level shifted multi-carrier modulation proposes better harmonic attenuation, but also offers an unequal device condition. Of all the level shifting methods phase disposition method gives the efficient result. Hence PD modulation is performed in this work which has been represented in Fig. 4.A Q-level inverter using level shifted multicarrier modulation technique needQ-1 triangular carriers, all having similar frequency and peak to peak amplitude, hence for 11-level inverter, 10 carriers are used. The Q-1 triangular carriers are vertical likely such that the bands they inhabit are connecting. The frequency modulation index $\mathrm{m}_{\mathrm{f}}$ remains same and is demarcated as given under equation

$$
m f=\frac{f c}{f s}
$$

The Amplitude modulation index $\left(\mathrm{m}_{\mathrm{a}}\right)$ is defined as shown in equation 3 .

$$
m a=\frac{V m}{\operatorname{Vcr}(n i 1)}
$$

Where, $\mathrm{V}_{\mathrm{m}}$ is the peak amplitude of the modulating signal and $\mathrm{V}_{\mathrm{cr}}$ is the peak amplitude of each carrier signal and $\mathrm{n}$ is the number of levels in the inverter [17 - 18].

The outcomes are further complimented to voltage level, which is need at the output end of the inverter. In this paper, there are 11 level inverter whose levels are $0, \pm \mathrm{V}, \pm 2 \mathrm{~V} \pm 3 \mathrm{~V} \pm 4 \mathrm{~V}$ and $\pm 5 \mathrm{~V}$, its carrier set are assigned to have different switching frequency of $2000 \mathrm{~Hz}$. The simulation model of eleven level MCPWM is depicted in Fig. 3. The subsystem gives the comparison of the sine wave which is the modulated signal with the carrier signal. When the reference signal is higher than or equal to the carrier signal, then the output is above the reference; otherwise, it will be below the reference. The main subsystem model for the 11 level inverter is depicted in Fig. 5. 


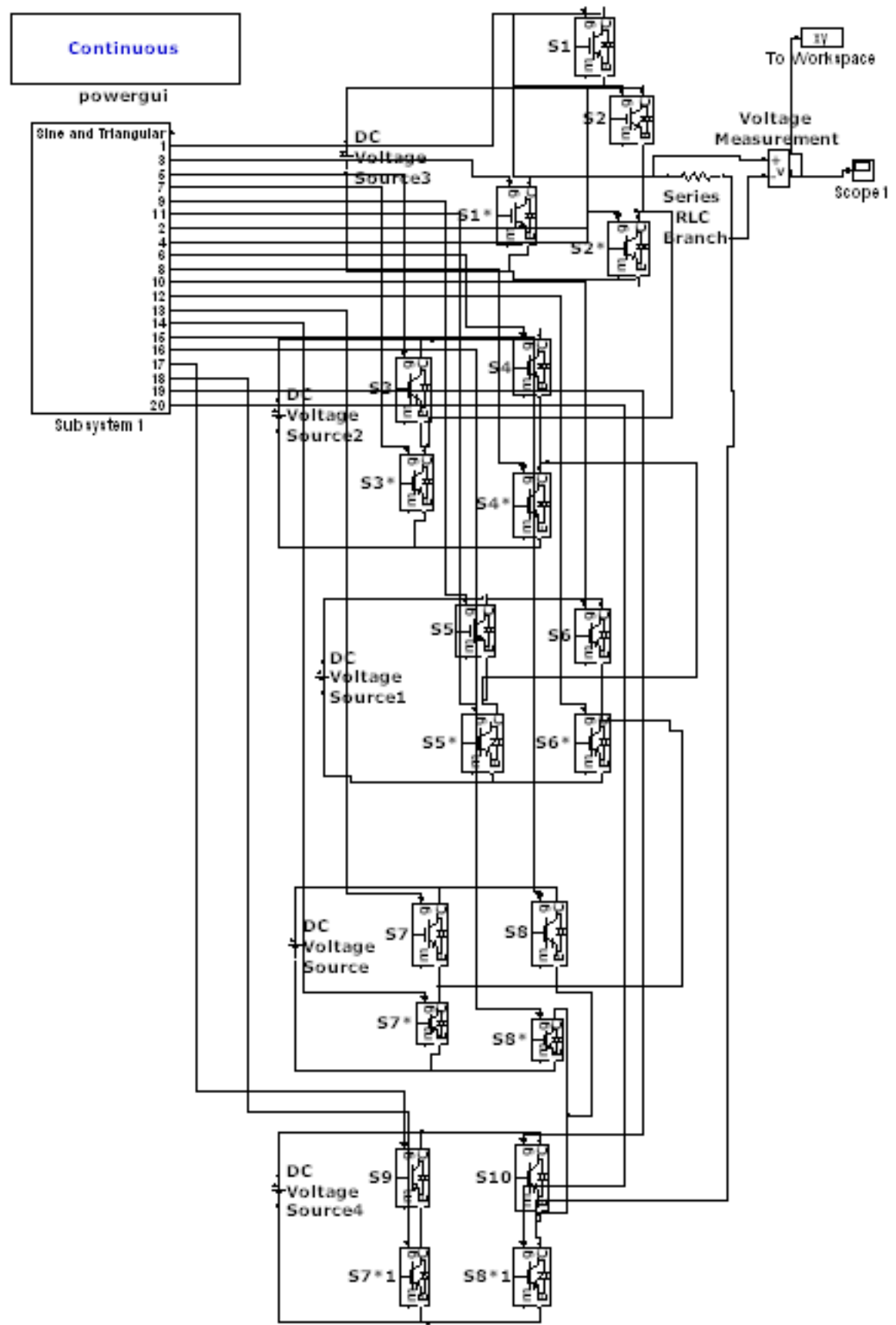

Fig. 3. Simulink model of eleven level MCPWM

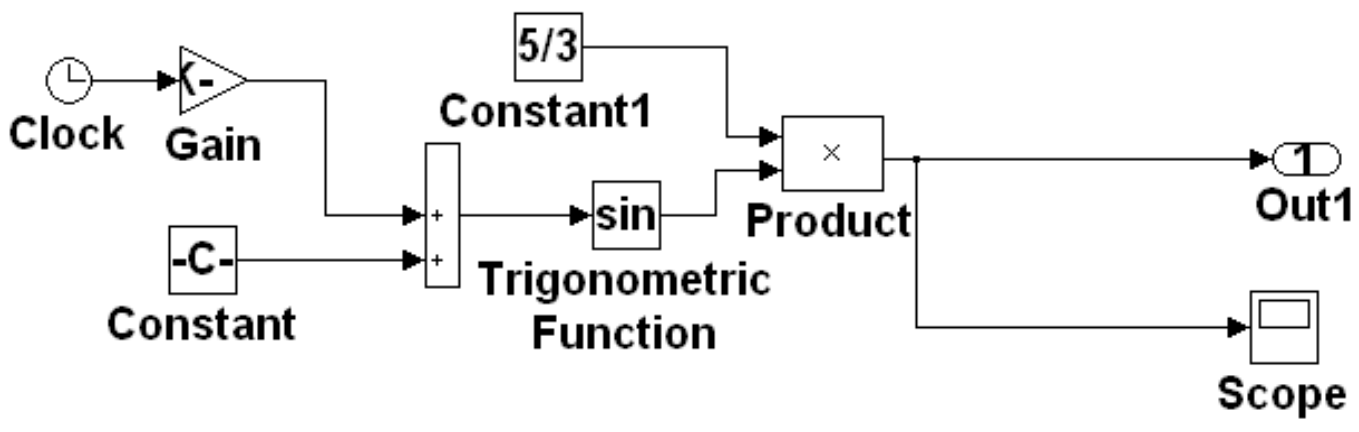

Fig. 4.Sinusoidal Subsystem 


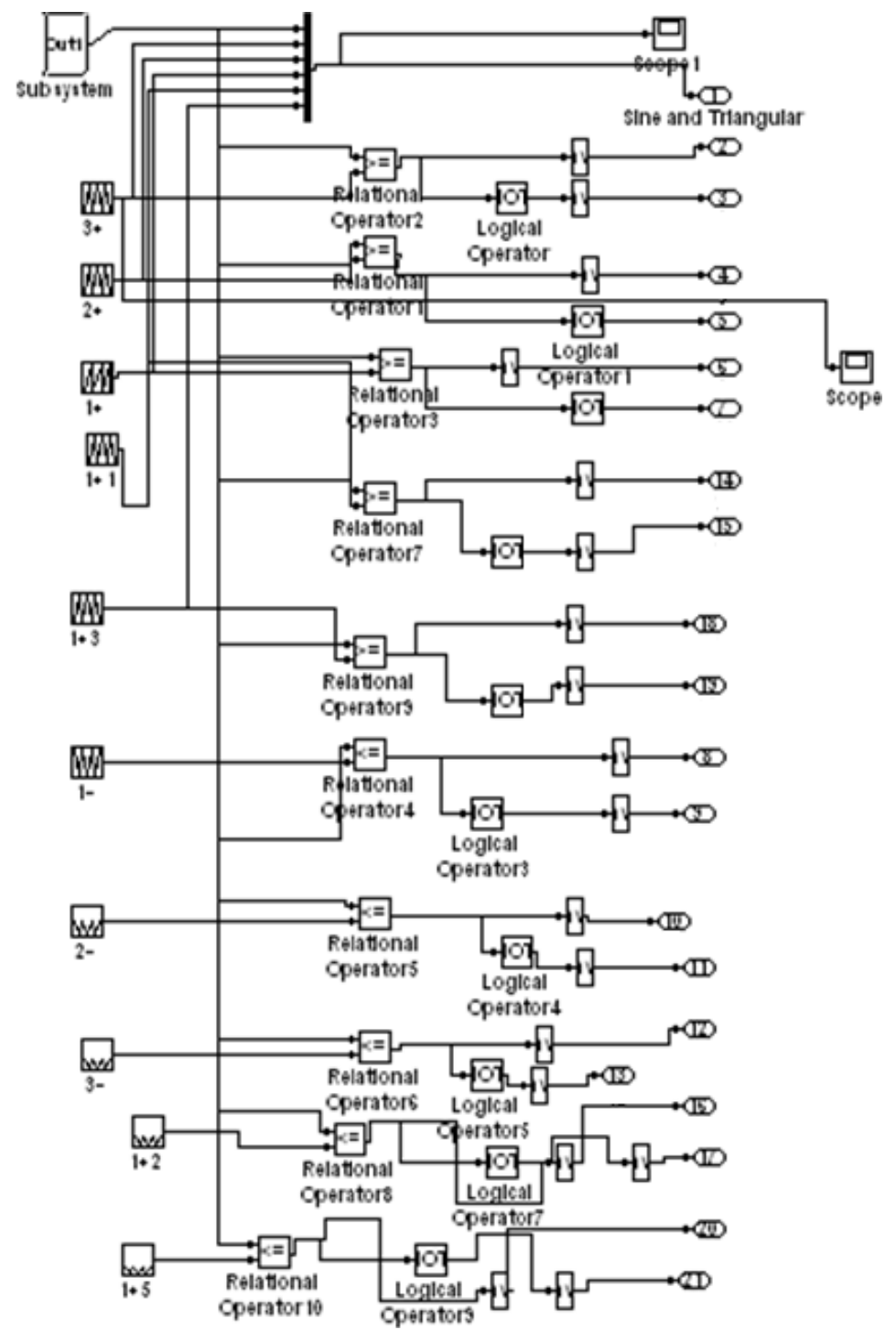

Fig. 5. Subsystem representation of MCPWM

\section{SIMULATION RESULTS}

The supply voltage $\left(\mathrm{V}_{\mathrm{dc}}\right)$ of $325 \mathrm{~V}$, Carrier frequency $(\mathrm{Fc})$ of $10 \mathrm{~K} \mathrm{~Hz}$, Supply frequency $(\mathrm{Fs})$ of $50 \mathrm{~Hz}$, Modulation Index of 200 [The term modulation index is defined as ratio of carrier frequency to supply frequency i.e. $\mathrm{M}=\mathrm{Fc} / \mathrm{Fs}$ ] are considered The outputs from simulation for $\mathrm{R}$ load is presented.The circuit diagram of three phase eleven level multi-level inverter is depicted in Fig.6, the subsystem model forthree phase 11 level inverter is depicted in Fig. 7. The output waveform and FFT harmonic spectrum is shown for both single phase and three phase R load in Fig. 8 and Fig. 9 respectively.The output waveform and FFT harmonic spectrum is shown for a single phase and three phase MCPWM with R load is represented in Fig.10 and Fig.11 respectively.

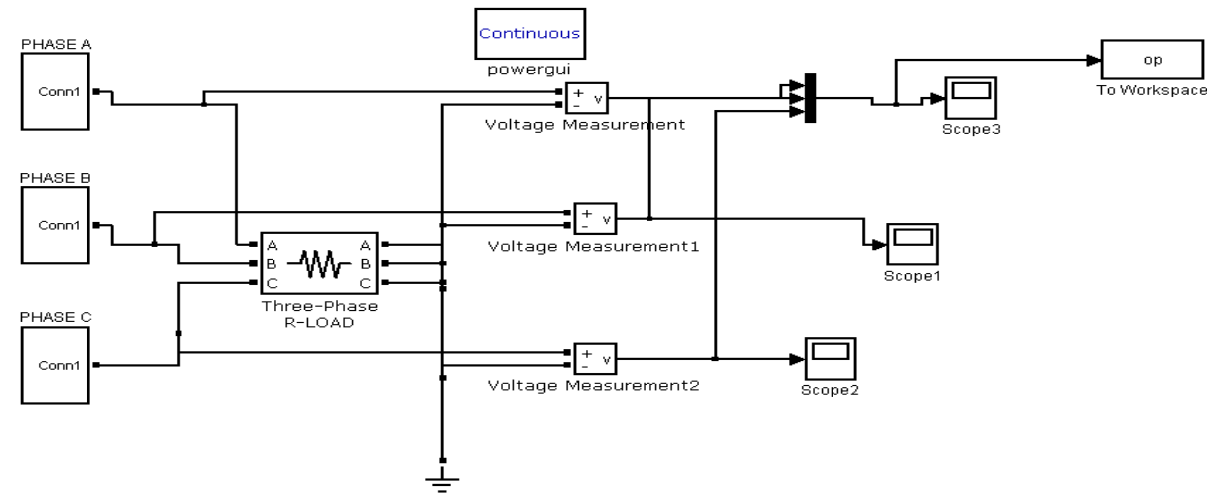

Fig. 6. Three phase 11 level MCPWM 


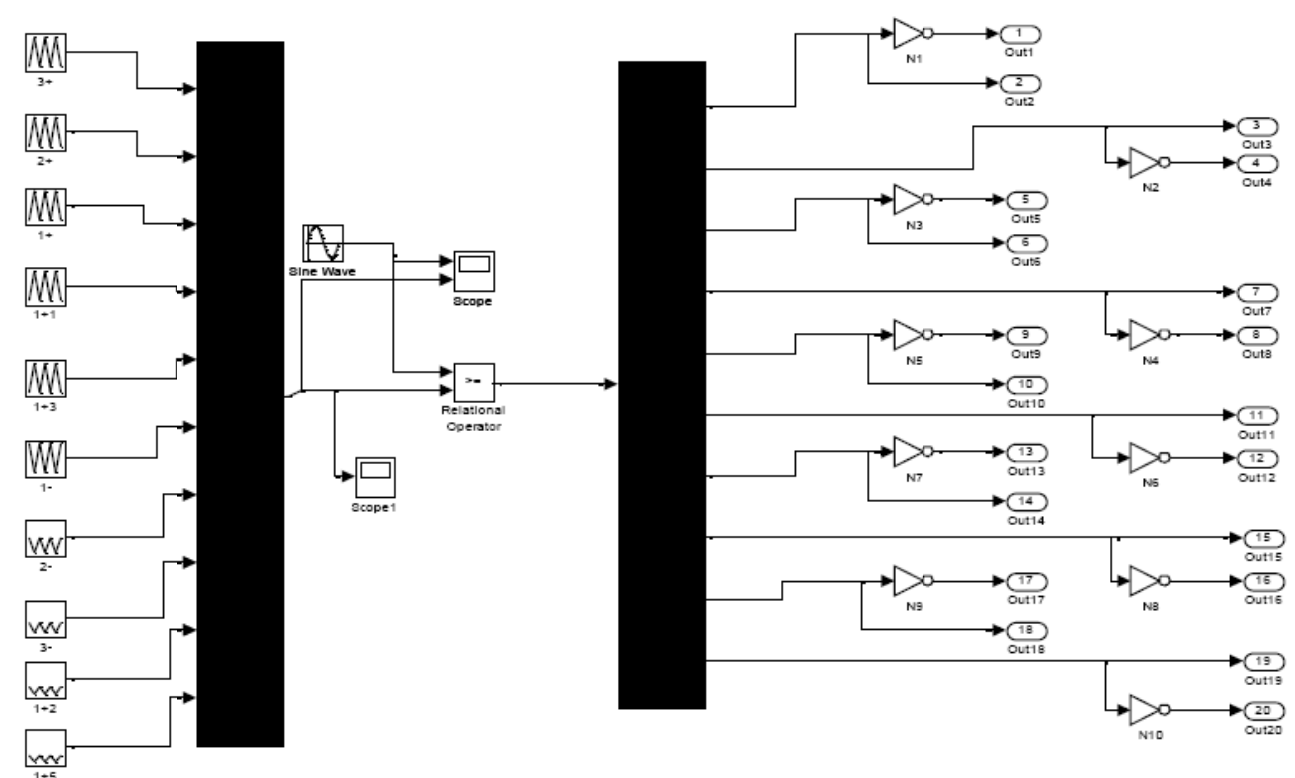

Fig. 7. Subsystem of single phase MCPWM

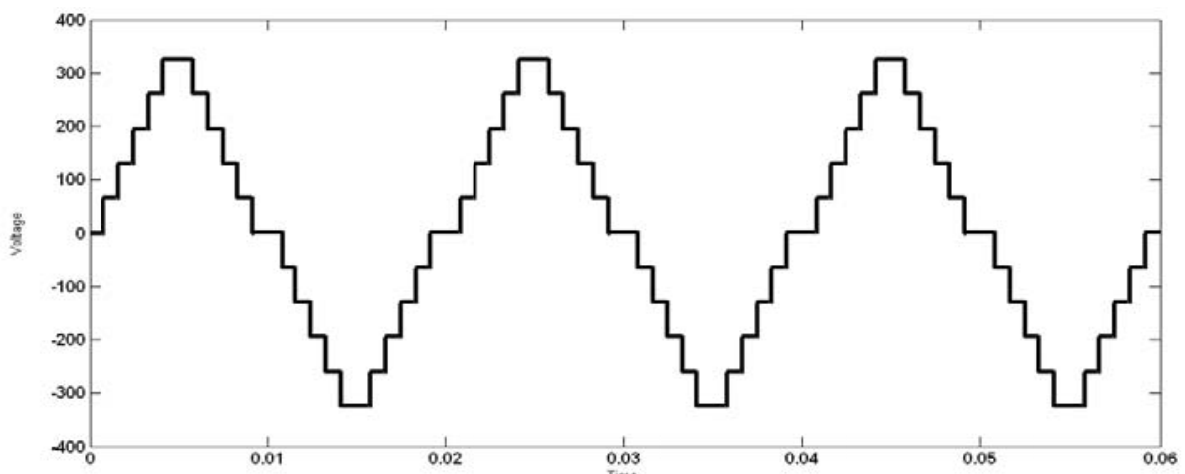

(a)

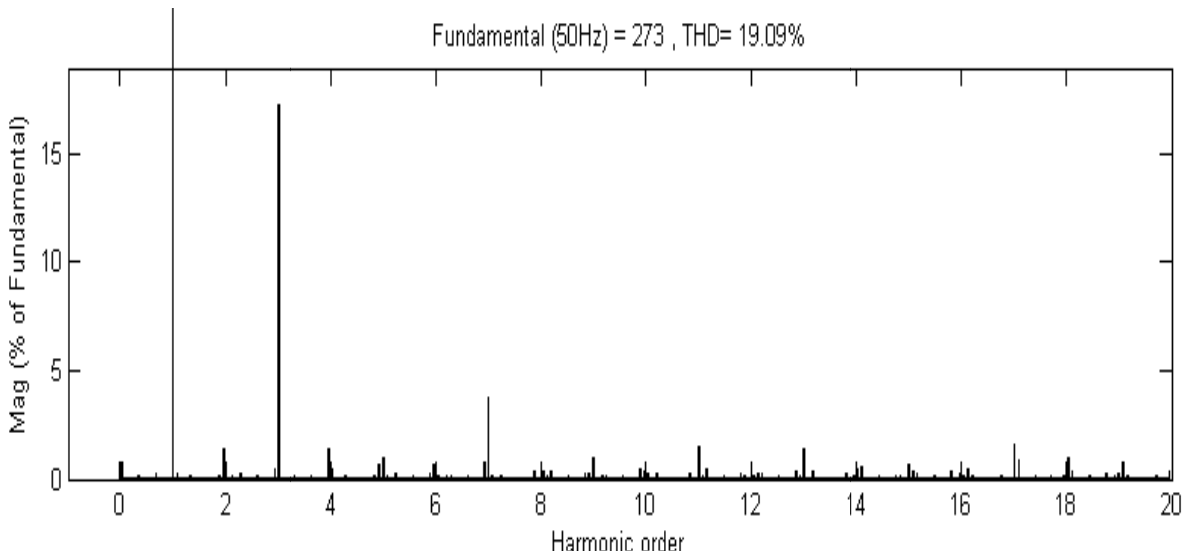

(b)

Fig. 8. (a)Single phase output voltage waveform (b) Harmonic spectrum 


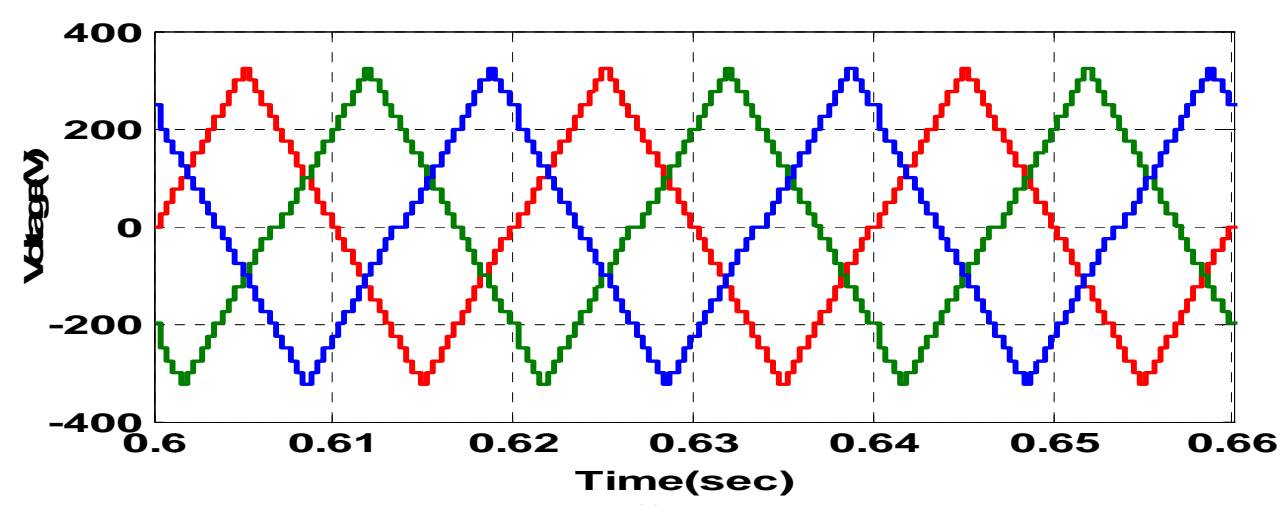

(a)

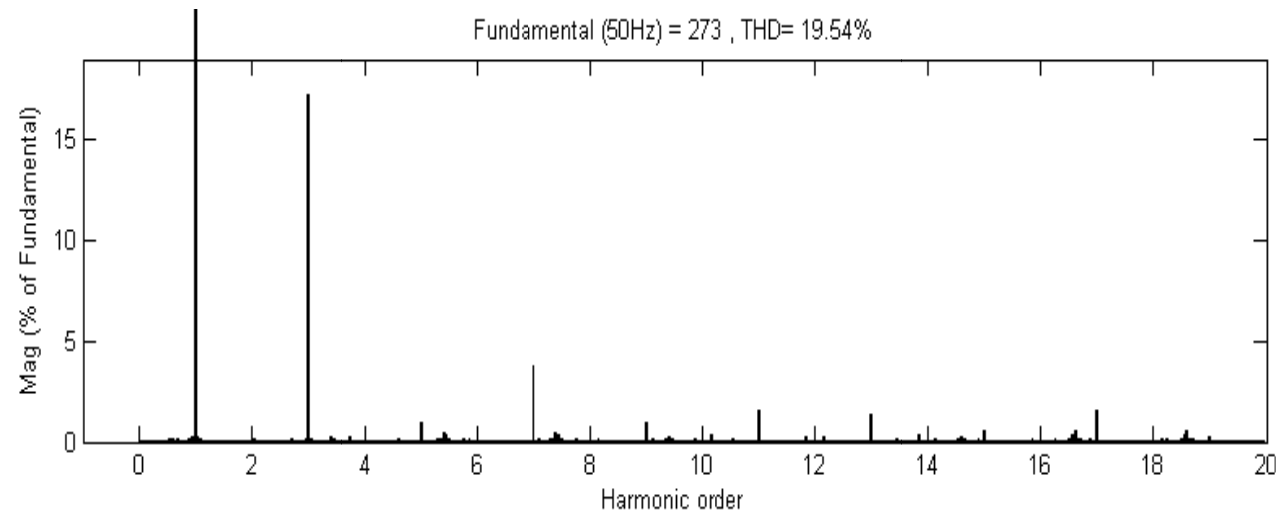

(b)

Fig. 9.(a) Three phase output voltage waveform (b) Harmonic spectrum
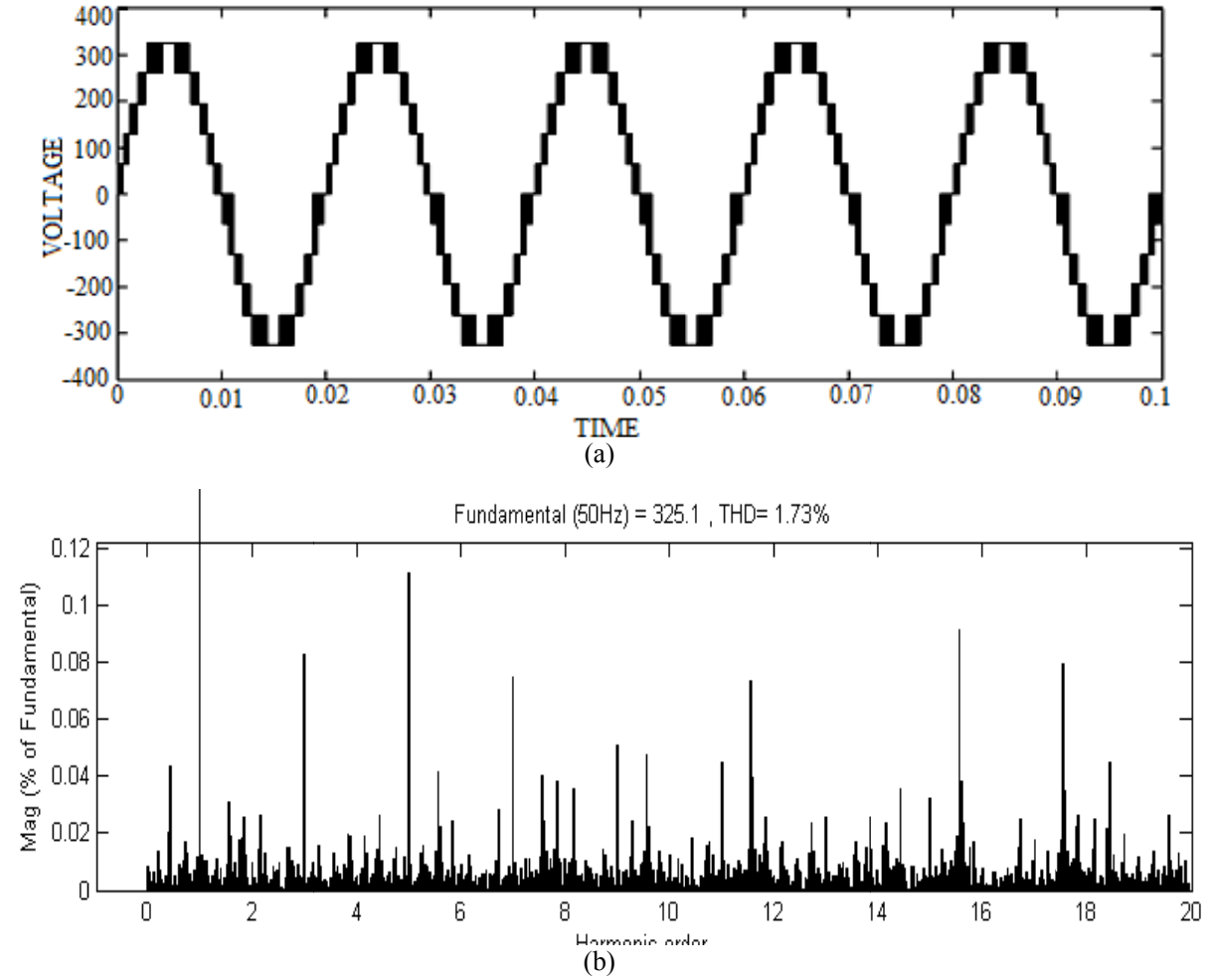

Fig. 10. (a)Single phase MCPWM output voltage waveform (b) Harmonic spectrum 


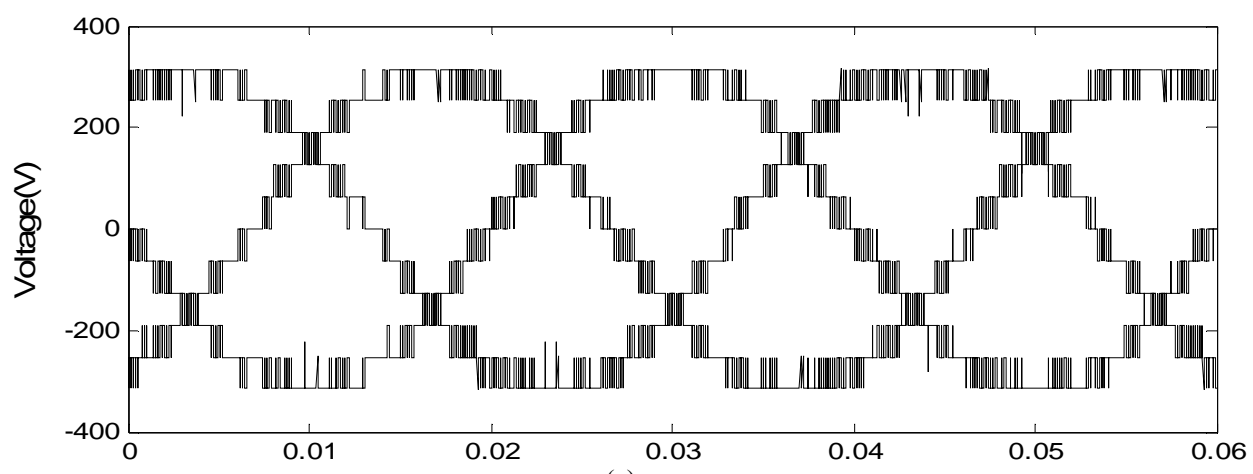

(a)

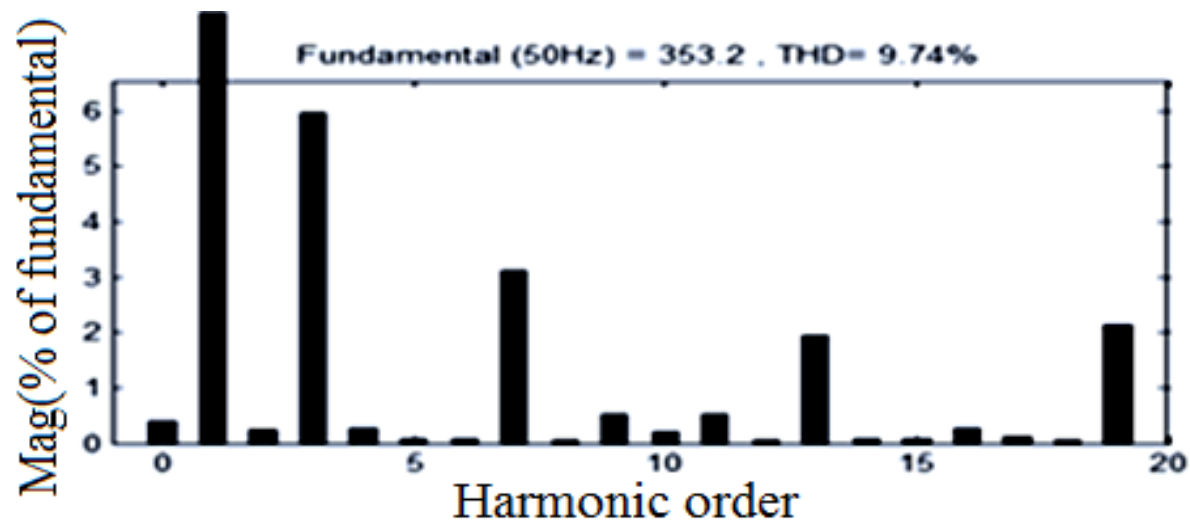

(b)

Fig. 11. (a)Three phase MCPWM output voltage waveform (b) Harmonic spectrum

\section{CONCLUSION}

Photovoltaic fed Symmetric MLI with multicarrier topology has been presented.Simulink models for level shifting Phase disposition method were presented. This paper deals with symmetrical MLI. The behavior of Symmetric MLI is presented with and without implementingMulticarrier strategy. Also complete analysis for 11- levels multi level inverter has been presented and it is shown a significant amount of THD reduction. The single phase and three phase circuits of this configuration with R-load and RL-load have been simulated using MATLAB / SIMULINK. The output waveforms and harmonics spectrums are presented. The results of both the technique are compared against the value of the THD. It is proved that MCPWM inverter THD is comparatively lesser than MLI.

\section{REFERENCES}

[1] Elena Villanueva, Pablo Correa, José Rodriguez, and Mario Pacas, "Control of a Single-Phase Cascaded H- Bridge Multilevel Inverter for Grid-Connected Photovoltaic Systems",IEEE Transactions on Industrial Electronics, Vol. 56, No. 11, Nov. 2009.

[2] H. L. Tsai, C. S. Tu, Y.J. Su, "Development of generalized photovoltaicmodel using MATLAB/SIMULINK",Proceedings of the World Congress on Engineering and Computer Science (WCECS), San Francisco, CA, 2008

[3] J. Rodriguez, J. S. Lai and F. Z. Peng, "Multilevel inverters: Survey of topologies, controls, and applications," IEEE Trans. Ind. Applica., vol.49, no. 4, pp. 724-738, Aug. 2002.

[4] Carrara, Gardella, Marchesoni, G. Sciutto(jul.1992), 'A new multilevel PWM method: A theoretical analysis,' IEEE Trans. Power Electron., vol. 7, no. 3, pp. 497-505, Jul.1992.

[5] Malinowski.M, Gopakumar.K, Rodr'iguez.J, and Perez.M.A. 'A survey on cascaded multilevel inverters,' IEEE Trans. Ind. Electron., vol. 57 , no. 7, pp. 2197-2206, Jul. 2010.

[6] Loh, Holmes, and Lipo, "Implementation and control of multilevel inverters with minimal harmonic distortion and common-mode voltage.’'IEEETrans.Power Electron.,vol. 20, no. 1,pp. 90-99, Jan. 2005.

[7] J. Rodríguez, B. Wu, S. Bernet, J. Pontt, and S. Kouro, "Multilevelvoltage-source-converter topologies for industrial medium-voltage drives," IEEE Trans. Ind. Electron., vol. 54, no. 6, pp. 2930-2945, Dec. 2007.

[8] Jae-hyunJeon, Tae-Jin Kim, Dae-wook Kang, and Dong-seok Hyun, "A SymmetricTechnique of CRPWM for Voltage Balance Method of Flying Capacitor Multi-level Inverter," IEEE Transactions on Industrial Electronics, Vol.52 , No. 3, June 2005, pp. 27592763.

[9] K.Surya Suresh, M.VishnuPrasad,"PV Cell Based Five Level Inverter Using Multicarrier PWM “International Journal of Modern Engineering Research, Vol.1, Issue.2, pp-545-551.

[10] Jae-hyunJeon, Tae-Jin Kim, Dae-wook Kang, and Dong-seok Hyun, A Symmetric Carrier Technique of CRPWM for Voltage Balance Method of Flying Capacitor Multi-level Inverter, IEEE Transactions on Industrial Electronics, Vol.52 , No. 3, June 2005, pp. 27592763.

[11] Bhagawat. P.M andStefanovic. V.R,"Generalized structure of a multilevel PWM inverter "IEEE Transactions on Industry Application,Vol.1.1983.

[12] Bakhshai.A,jain.P and ,Khajehoddi, “A review of single-phase grid connected photovoltaic systems,”In Proc. IEEE Epc, Montreal, Qc,Canada.July 2007. 
[13] Z. Du, L. Tolbert, and J. Chiasson, "Active harmonic elimination for multilevel converters," IEEE Trans. Power Electron., vol. 21, no. 2, pp.45 469, Mar. 2006.

[14] Calais, M.; Borle, L.J.; Agelidis, V.G., Analysis of multicarrier PWM methods for a single-phase five level inverter, Power Electronics Specialists Conference,PESC.2001 IEEE 32nd Annual, Volume 3, Issue, 2001. pp:1351 - 1356.

[15] B. P. McGrath and D. G. Holmes, "Multicarrier PWM strategies for multilevel inverters,"IEEE Trans. Ind. Electron., vol. 49, no. 4, pp. 858-867, Aug. 2002.

[16] R. Gupta, A. Ghosh, and A. Joshi, "Switching characterization of cascaded multilevel-inverter-controlled systems,"IEEE Trans. Ind. Electron., vol. 55, no. 3, pp. 1047-1058, Mar. 2008

[17] R. Naderi and A. Rahmati, "Phase shifted carrier PWM technique for general cascaded inverters," IEEE Trans. Power Electron., vol. 23, no. 3, pp. 1257-1269, May 2008.

[18] J. H. Kim, S. K. Sul, and P. N. Enjeti, "A carrier based PWM method with optimal switching sequence for a multilevel four-leg voltage source inverter,” IEEE Trans. Ind. Applications., vol. 44, no. 4, pp. 1239-1248, Jul. 2008.

\section{AUTHOR PROFILE}

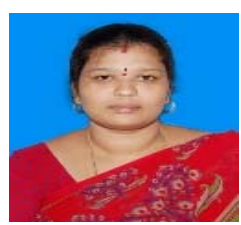

Dr.J.Gayathri Monicka is a Associate Professor in EEE Department at Adhi College of Engineering and Technology. She has received B.E and M.Tech degree in Electrical and Electronics Engineering. She was awarded Doctorate in Electrical Engineering by Anna University in field of Power Electronics and Drives .Her research area includes Multilevel Inverter, Renewable Energy and Motor drives.

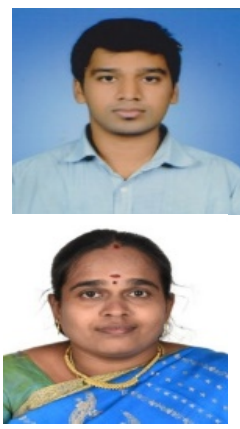

Mr. K. Dwarakesh completed B.E in Electrical and Electronics Engineering \& M.E in Power Electronics and Drives. He is presently working in Adhi College of Engineering and Technology as Assistant Professor in the Department of Electrical and Electronics Engineering

Dr.C. Amuthadevi completed her B.E and M.E in the discipline of Computer Science and Engineering. She has completed PhD in Anna University in the year 2016. Her field of research in data- mining, image processing. 